\title{
Flying spiders: A reconfigurable spider drone for education
}

\author{
Rakshanda Alam ${ }^{1}$, Rafiq Ahmad ${ }^{1}$ \\ ${ }^{1}$ Faculty of Engineering, University of Alberta
}

\begin{abstract}
Unmanned Aerial Vehicles, most commonly known as drones are the raging fire of this generation. Attracting a vast age ranges from children to adults. Not only can drones be used for fun, but they can inspect dangerous places for humans which reduces health risks. These facts helped create the curiosity to research how a drone works and different designs. The reason for which, the main purpose of this research was to come up with a design that will have all the components necessary for a drone to function. Additionally, a safe design that will protect the body (the brain too) of the drone. That is the most expensive and important, whereas the arms and propellers are easy to repair and cheaper. Therefore, the first step of the methodology was the idea generation. This research was inspired by things seen around from day-to-day. In particular, spiders, shuriken (Japanese throwing knife) and step stools. The incorporation of the two led to the next step of the methodology of mechanical engineering design known as task classification. The main objective being safety and efficiency. Moving on to the third step being concept design, where three drones needed to be designed, later choosing the safest and efficient one. The final and fourth step being detailed design. Where the best design, being the upside-down spider, is chosen for LEGO Digital Design. This step was the most important one for future research purposes. For example, the correct components and pieces had to be present for the drone to be used as a step by step assembly station for third and fourth-year mechanical engineers. To conclude, the spider drone was the best design because its arms which are like spider legs gave more lift to the drone which made it perform before and protecting the body, also known as the brain. That is the most expensive part of the drone, and the arms are the inexpensive part that can be easily replaced. Additionally using legos as the main building material let the parts be used for other things such as cars and planes. For that reason, the upside-down spider was the best choice.
\end{abstract}

Key words:

Reconfigurable, Alberta Education, LIMDA

Cite as: Alam R. and Ahmad, R. 2019. Flying spiders: A reconfigurable spider drone for education. Alberta Academic Review, Vol 2 (2) 3-4, WISEST Special Issue (not peer-reviewed), DOI: 10.29173/aar37. 

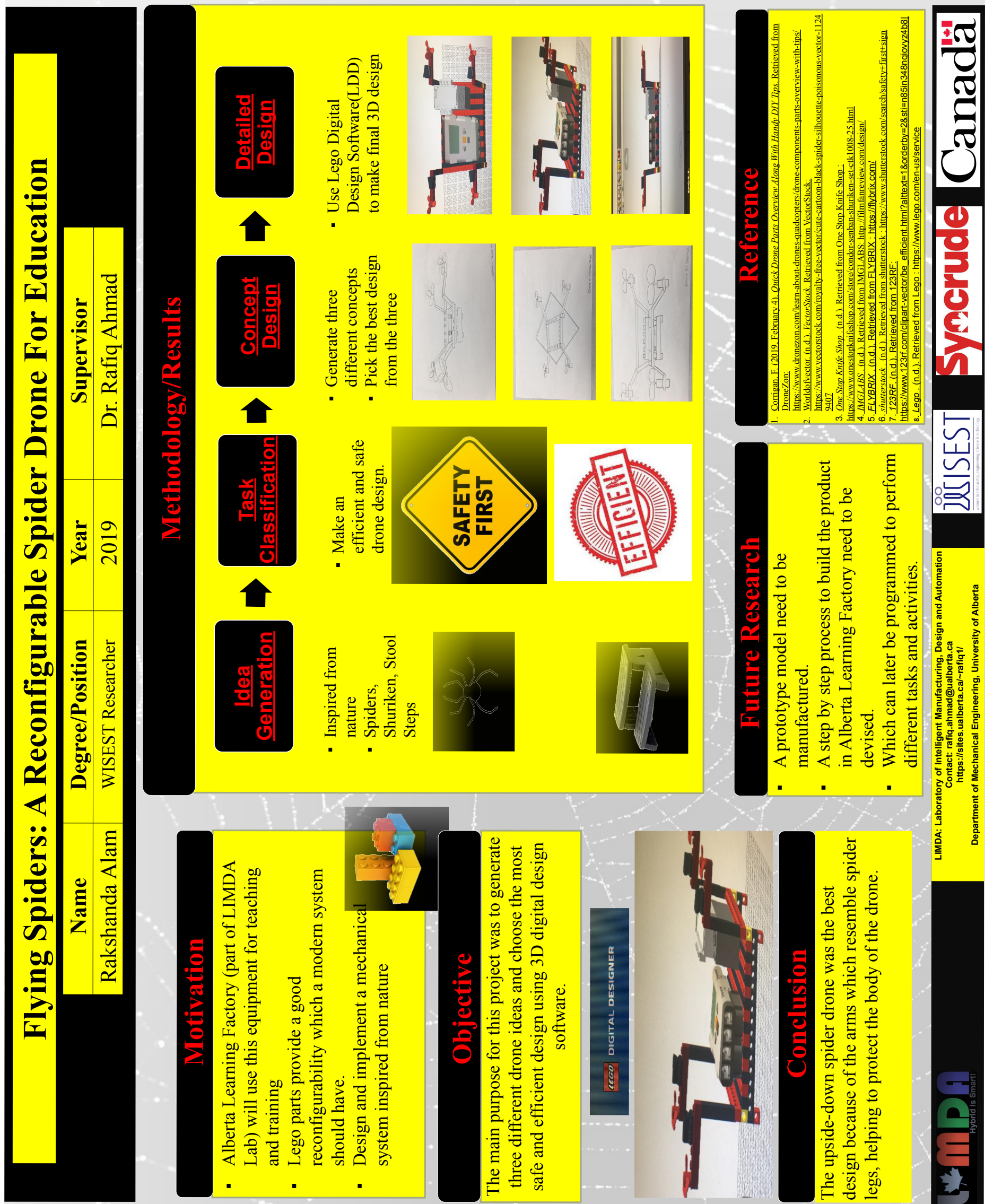